\title{
Open ocean DMS air/sea fluxes over the eastern South Pacific Ocean
}

\author{
C. A. Marandino ${ }^{1, *}$, W. J. De Bruyn ${ }^{2}$, S. D. Miller ${ }^{3}$, and E. S. Saltzman ${ }^{1}$ \\ ${ }^{1}$ Dept. of Earth System Science, University of California, Irvine, Irvine, CA, USA \\ ${ }^{2}$ Dept. of Physical Science, Chapman University, Orange, CA, USA \\ ${ }^{3}$ Center for Atmospheric Research, SUNY, Albany, Albany, NY, USA \\ * now at: IFM-GEOMAR Marnie Biogeochemie/Chemische Ozeanographie in Kiel, Germany
}

Received: 9 April 2008 - Published in Atmos. Chem. Phys. Discuss.: 18 June 2008

Revised: 28 August 2008 - Accepted: 21 October 2008 - Published: 16 January 2009

\begin{abstract}
Air/sea fluxes of dimethylsulfide (DMS) were measured by eddy correlation over the Eastern South Pacific Ocean during January 2006. The cruise track extended from Manzanillo, Mexico, along $110^{\circ} \mathrm{W}$, to Punta Arenas, Chile. Bulk air and surface ocean DMS levels were also measured and gas transfer coefficients $\left(k_{\mathrm{DMS}}\right)$ were computed. Air and seawater DMS measurements were made using chemical ionization mass spectrometry (API-CIMS) and a gas/liquid membrane equilibrator. Mean surface seawater DMS concentrations were $3.8 \pm 2.2 \mathrm{nM}$ and atmospheric mixing ratios were $340 \pm 370 \mathrm{ppt}$. The air/sea flux of DMS was uniformly out of the ocean, with an average value of $12 \pm 15 \mu \mathrm{mol} \mathrm{m}^{-2} \mathrm{~d}^{-1}$. Sea surface concentration and flux were highest around $15^{\circ} \mathrm{S}$, in a region influenced by shelf waters and lowest around $25^{\circ} \mathrm{S}$, in low chlorophyll gyre waters. The DMS gas transfer coefficient exhibited a linear wind speed-dependence over the wind speed range of 1 to $9 \mathrm{~m} \mathrm{~s}^{-1}$. This relationship is compared with previously measured estimates of $k$ from DMS, $\mathrm{CO}_{2}$, and dual tracer data from the Atlantic and Pacific Ocean, and with the NOAA/COARE gas transfer model. The model generated slope of $k$ vs. wind speed is at the low end of those observed in previous DMS field studies.
\end{abstract}

\section{Introduction}

The physics, chemistry, and biology of the air/sea interface are not well understood. As a result, estimates of air/sea gas transfer rates are usually based on simple parameterizations. Air/sea fluxes $(F)$ of trace gases are usually described as the

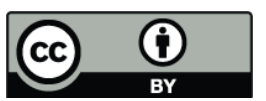

Correspondence to: C. A. Marandino (cmarandi@uci.edu) product of a gas transfer coefficient $(k)$ and a difference in gas partial pressure between the surface ocean and overlying atmosphere $(\Delta C)$,

$F=k \Delta C$

The gas transfer coefficient is constrained by field observations of the evasion of deliberate, inert gases, and the uptake of ${ }^{14} \mathrm{C}$ by the oceans. The gas transfer coefficient can also be estimated from micrometeorological flux measurements, such as eddy covariance, profile, or relaxed eddy accumulation, in conjunction with air/sea concentration measurements. Most parameterizations of the gas transfer coefficient utilize wind speed as the sole controlling parameter. However, it is clear that many factors which influence turbulence near the air/sea interface affect rates of gas transfer. These include buoyancy effects, surface tension (microlayer effects), whitecap formation and bubble breaking, and wind/wave interactions (Donelan and Wanninkhof, 2002 and references therein). Gas exchange models of increasing sophistication have been developed, based on similarity theory and energy balance considerations, but these are also highly parameterized, and based on limited observational data (Fairall et al., 1996a, b, 2000; Hare et al., 2004; Soloviev, 2007; Soloviev and Schlussel, 1994, 1996).

Oceanic emissions of dimethylsulfide (DMS) are important because of their role as a precursor of atmospheric sulfate aerosol. DMS is also a useful gas for studying air/sea transfer, because it is produced throughout the surface oceans, and has an atmospheric lifetime of only a few days. The resulting air/sea gradient is always from the ocean to the atmosphere and the resulting flux is superimposed on a low background atmospheric DMS level (up to hundreds of ppt). Consequently, DMS fluxes are well suited to measurement by micrometeorological techniques. Hintsa et al. (2004) and

Published by Copernicus Publications on behalf of the European Geosciences Union. 


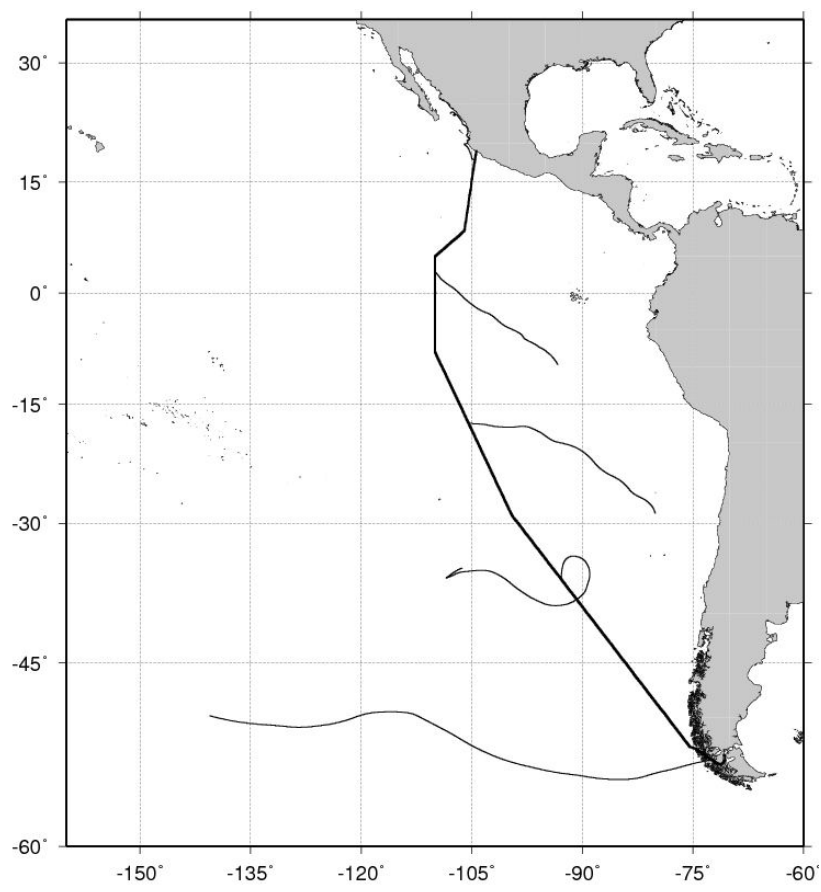

Fig. 1. Cruise track for the Knorr_06. Solid grey lines are five day surface air mass back trajectories.

Zemmelink et al. (2004) employed the gradient and relaxed eddy accumulation techniques to measure DMS fluxes in coastal waters. Eddy correlation measurements require the use of a fast response $(\sim 1 \mathrm{~s})$ chemical sensor. Advances in the development of atmospheric pressure chemical ionization mass spectrometry (API-CIMS) have made such measurements feasible for DMS. Eddy correlation has been used successfully to measure DMS open ocean fluxes in the Pacific and Atlantic Oceans (Huebert et al., 2004; Marandino et al., 2007; Blomquist et al., 2006).

In this study, eddy correlation measurements of open ocean air/sea DMS fluxes were made using API-CIMS on a January 2006 cruise aboard the R/V Knorr in the southeastern Pacific Ocean (Knorr_06). Atmospheric and surface seawater bulk DMS levels were also measured and the gas transfer coefficient was derived. The cruise started in Manzanillo, Mexico $\left(19^{\circ} \mathrm{N}-104^{\circ} \mathrm{W}\right)$ on 3 January 2006 , headed southwest and crossed the equator at $110^{\circ} \mathrm{W}$, then headed southeast to Punta Arenas, Chile on 25 January 2006 (Fig. 1). Data are reported for 10 to 24 January 2006, corresponding with latitudes 0 to $55^{\circ} \mathrm{S}$. These data are compared to the existing database of open ocean DMS and $\mathrm{CO}_{2}$ flux measurements from both the Atlantic and Pacific oceans (Blomquist et al., 2006; Huebert et al., 2004; Marandino et al., 2007; McGillis et al., 2001, 2004).

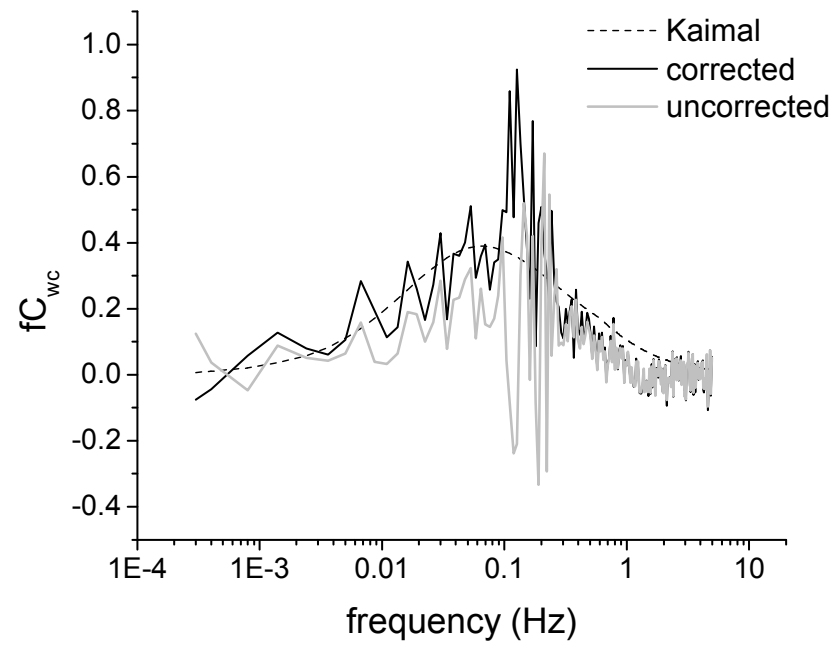

Fig. 2. DMS w frequency weighted cospectra from the morning of 11 January 2006. The solid black line is the cospectrum corrected for ship motion, solid grey is the motion uncorrected cospectrum, and the dashed line is the idealized scalar cospectrum from Kaimal et al. (1972).

\section{Methods}

\subsection{Experimental setup}

Atmospheric pressure chemical ionization mass spectrometry (API-CIMS) was used to measure the air/sea concentration gradient and eddy correlation flux of DMS. The APICIMS instrument and experimental setup have been described in detail by Marandino et al. (2007), and are briefly described here. The API-CIMS instrument was located in the upper laboratory of the ship. Air from the ship's bow mast (approximately $7 \mathrm{~m}$ above the sea surface) was drawn through a $90 \mathrm{~mm}$ diameter Teflon filter housing and $55 \mathrm{~m}$ of $0.8 \mathrm{~cm}$ ID Teflon tubing at approximately $36 \mathrm{~L} \mathrm{~min}^{-1}$ STP to the ship's lab. From that air flow, $1.7 \mathrm{~L} \mathrm{~min}^{-1}$ STP was drawn into the API-CIMS ion source through a single tube Nafion membrane. Three dimensional wind speed, direction, and ship motion were measured on the bow mast with a Campbell CSAT-3 sonic anemometer and MotionPak II (Systron Donner).

Surface seawater DMS from the ship scientific seawater supply (5 m depth) was analyzed using a Liqui-Cel $2.5 \times 8$ membrane equilibrator (Membrana). The equilibrator was configured such that the seawater passed over the outside of a bundle of polypropylene tubes. Zero air (Aadco Instruments) passed through the tubes to be equilibrated with the seawater and was directed to the API-CIMS. Approximately $0.30 \mathrm{~L} \mathrm{~min}^{-1}$ STP of zero air was equilibrated with $3 \mathrm{~L} \mathrm{~min}^{-1}$ of seawater. The temperature of the seawater in the equilibrator was monitored constantly using a GE thermistor with a Texas Instruments analog interface/display, in order to compute the Henry's Law solubility. The 

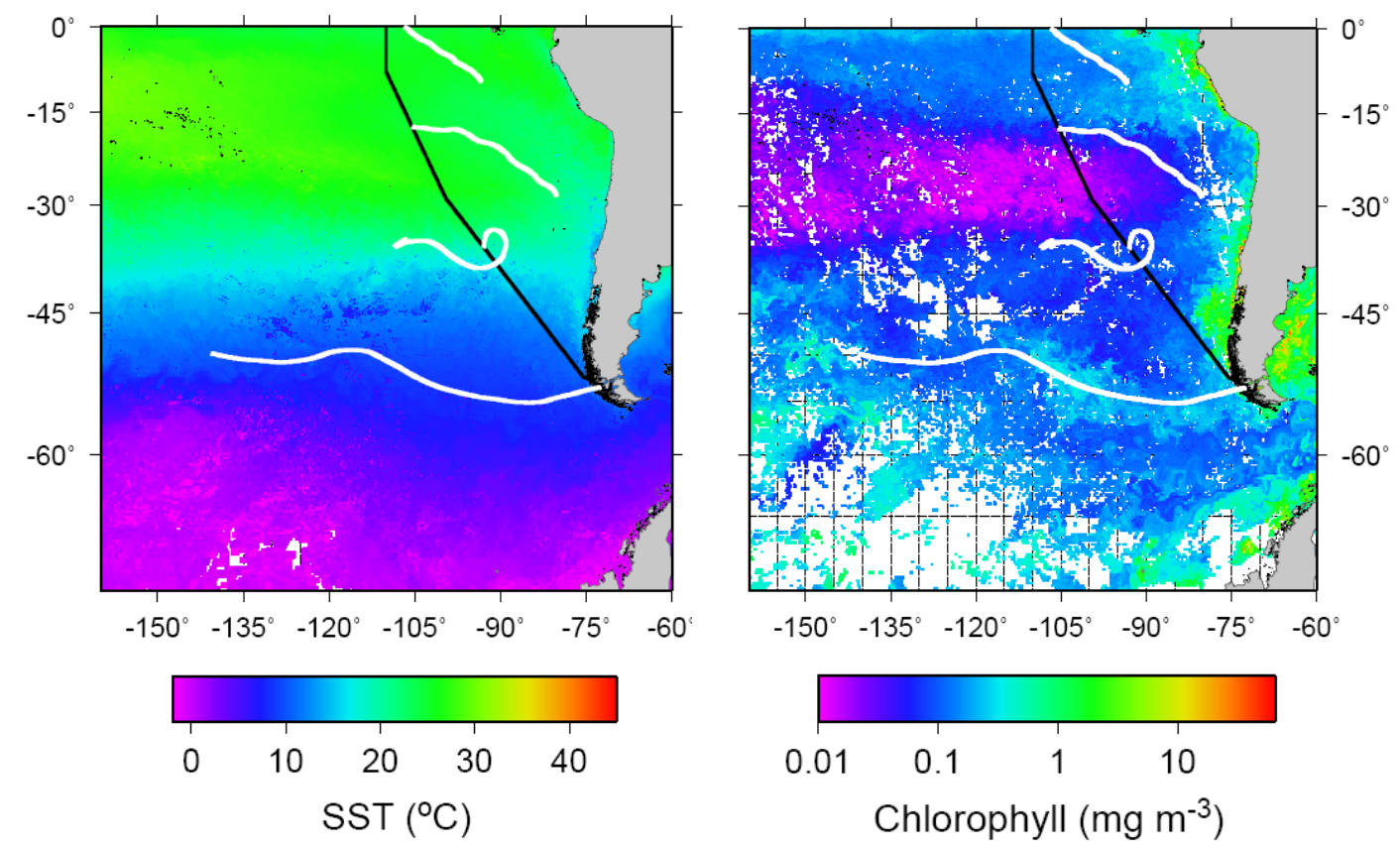

Fig. 3. The cruise track superimposed on Modis data. Left panel - SST $\left({ }^{\circ} \mathrm{C}\right)$. Right panel - chlorophyll $\left(\mathrm{mg} \mathrm{m}^{-3}\right)$. Solid white lines are 5 day surface air mass back trajectories.

equilibrator temperature was approximately $1.5^{\circ} \mathrm{C}$ warmer than sea surface temperature measured using the ship sensors.

An internal trideuterated DMS gas standard (2.24 ppm) was continuously added to the ambient air and seawaterequilibrated air streams ( 9 and $2 \mathrm{~mL} \mathrm{~min}^{-1} \mathrm{STP}$, respectively). The measurement protocol for the API-CIMS was $15 \mathrm{~min}$ seawater analysis, one hour atmospheric analysis, then 15 min seawater analysis. During seawater measurements, system blanks were periodically acquired (every $1.5 \mathrm{~min}$ ) by bypassing the equilibrator using a multiport Valco valve. More extensive atmospheric and seawater blanks were measured every $12 \mathrm{~h}$.

During the cruise, API-CIMS sensitivity varied with the absolute humidity in ambient air and sea surface temperature, reflecting the impact of water vapor levels on instrument source ionization chemistry. The API-CIMS atmospheric measurement and seawater measurement sensitivities ranged from 5 to $70 \mathrm{cps} \mathrm{ppt}^{-1}$ and 10 to $190 \mathrm{cps} \mathrm{ppt}^{-1}$, respectively. The greater sensitivity of the seawater sampling system relative to the atmospheric setup was due to more favorable water vapor conditions and higher pressure in the API-CIMS ionization region. The flow rate and long sample tubing used to perform air measurements caused the pressure to be subambient (i.e. $0.7 \mathrm{~atm}$ ) at the API-CIMS source.

No covariance was observed between vertical wind and the isotope standard, confirming that water vapor fluctuations did not impact the flux measurements.

\subsection{Data processing and error analysis}

The eddy covariance data processing routine has been described in detail by Marandino et al. (2007). Fluxes, concentration gradients, and $k$ values were processed in one hour intervals. The data presented here have been corrected for ship motion, sensor misalignment, and high frequency attenuation in the sample tubing. After wind corrections, the vertical wind DMS cospectra looked similar to idealized cospectral representations of scalar fluxes in the atmospheric boundary layer from Kaimal et al. (1972) (Fig. 2). The magnitude of the high frequency attenuation correction was $25.4 \pm 15.7 \%$. Quality control criteria have been applied to identify data affected by flow distortion, heterogeneity in surface seawater DMS, and low frequency features in the flux cospectrum. The quality control tests resulted in the omission of 62 records out of 97.

The uncertainties in the measured fluxes and concentration gradients are approximately $\pm 25 \%$ and $\pm 10 \%$, respectively. The propagated uncertainty in the computed gas transfer coefficient is approximately $\pm 25 \%$.

\subsection{Ancillary data}

Chlorophyll concentrations and sea surface temperatures (SST) were obtained from MODIS AQUA (Fig. 3). Both products were the monthly average from January 2006 at $4 \mathrm{~km}$ resolution. A time series of chlorophyll along the cruise track was extracted from the MODIS data as 4-9 point averages. Significant wave height was obtained from TOPEX 
using the Aviso algorithm for 1 day periods at $1^{\circ} \times 3^{\circ}$ resolution and extracted in the same manner as the MODIS data. Significant wave heights during the Knorr_06 cruise were between 1.5 and $2.5 \mathrm{~m}$. Five-day mean satellite-derived surface currents were obtained from OSCAR. Currents were $<0.3 \mathrm{~ms}^{-1}$ over most of the cruise track. Between 0 and $8^{\circ} \mathrm{S}$ currents were easterly, between 0.5 and $0.7 \mathrm{~ms}^{-1}$. Waves and currents were neglected in the discussion of the gas transfer coefficient and were not used in any model runs.

Atmospheric boundary layer stability was calculated from shipboard data, and compared with the TOGA-COARE hfbulktc routine (Fairall et al., 1996b) with good agreement. Surface air mass back trajectories (5 day, isentropic) were calculated using the Hysplit model. The NOAA-COARE model (Fairall et al., 2000) was used to calculate gas transfer coefficients. The model is based on the COARE algorithm and computes the gas transfer coefficient using turbulent and diffusive mechanisms.

\section{Results and discussion}

\subsection{Knorr_06 cruise observations}

The Knorr_06 cruise traversed three broad oceanographic regions: equatorial upwelling, S. Pacific gyre, and subpolar waters (Fig. 4). The upwelling region was characterized by high chlorophyll levels and sea surface temperatures around $25^{\circ} \mathrm{C}$. The water temperatures in the gyre region were similar to the upwelling region, but chlorophyll levels were much lower. Subpolar waters ranged from 10 to $20^{\circ} \mathrm{C}$ with chlorophyll levels similar to those in the equatorial upwelling region. During the last 3 days of the cruise, the ship skirted high productivity coastal waters off Chile containing the highest levels of chlorophyll over the entire cruise track. Air mass back trajectories indicate southeasterly flow during passage through equatorial and gyre waters, and westerly flow over the subpolar waters. Elevated wind speeds were encountered on DOY 21 to 22 and 24, associated with the intersection of the cruise track with westerly low pressure systems. Atmospheric boundary layer stability was neutral $(\mathrm{z} / \mathrm{L} \sim 0)$ in the upwelling and subpolar front regions and unstable $(\mathrm{z} / \mathrm{L}<0)$ in the gyre region. The instability in the gyre region is most likely related to an increase in the air/sea temperature difference in that region.

Seawater DMS levels in the equatorial upwelling region ranged from 0 to $7 \mathrm{nM}$. Consistently low DMS levels were observed in gyre waters, ranging from 0 to $4 \mathrm{nM}$. The transitional regions into and out of the gyre were characterized by local maxima in DMS of 7 to $8 \mathrm{nM}$. The DMS levels in the subpolar front waters ranged from 0 to $22 \mathrm{nM}$, with the highest levels over the entire cruise track observed at $45^{\circ} \mathrm{S}$ (DOY 22). These measurements seem to be in good agreement with the limited seawater values presented in Huebert et al. (2004) for the region between the equator and

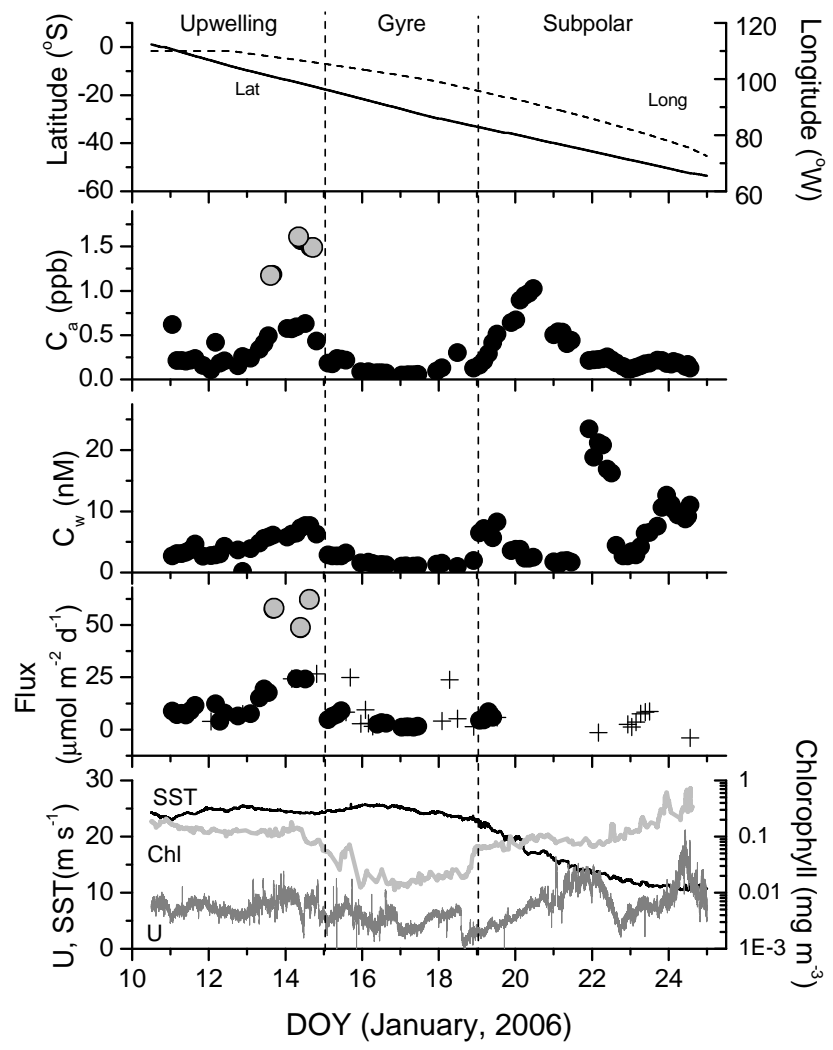

Fig. 4. Time series of shipboard data. From top: (a)- Cruise track latitude (solid) and longitude (dashed), (b) - DMS atmospheric mixing ratio, (c) - DMS oceanic concentration, (d) - DMS air/sea flux, in which closed circle represent the highest quality data used to compute $k$ and plus signs are other fluxes discussed in text, (e) - Sea surface temperature (solid black), horizontal wind speed (solid dark grey), and chlorophyll concentration (solid light grey). The vertical dashed lines indicate the upwelling, gyre, and subpolar front regions of the cruise. Grey closed circles indicate outlier points discussed in text.

$10^{\circ} \mathrm{S}$ (Huebert et al. (2004)'s data was measured between $7.5^{\circ} \mathrm{N}-7.5^{\circ} \mathrm{S}$ ). There is remarkable similarity between the data from this study and earlier DMS measurements by Bates and Quinn (1997) in February and March 1989 between the equator and $45^{\circ} \mathrm{S}$, along $110^{\circ} \mathrm{W}$ (Fig. 5). Both the measured levels and latitudinal trends were nearly exact matches between the two cruises, despite the nearly 20 year gap between measurements. The DMS levels from this study differed from the Bates and Quinn (1997) data when the cruise tracks were separated by more than 15 degrees longitude.

To the best of our knowledge, these data are the only published seawater DMS measurements made using a LiquiCel membrane equilibrator. Marandino et al. (2007) used a single-tube $\left(1 / 8^{\prime \prime} \mathrm{OD}\right)$ porous Teflon membrane in conjunction with a chemical ionization mass spectrometer to measure seawater DMS in the central and North Pacific. Huebert et al. (2004) used purge and trap GC/MS. The 


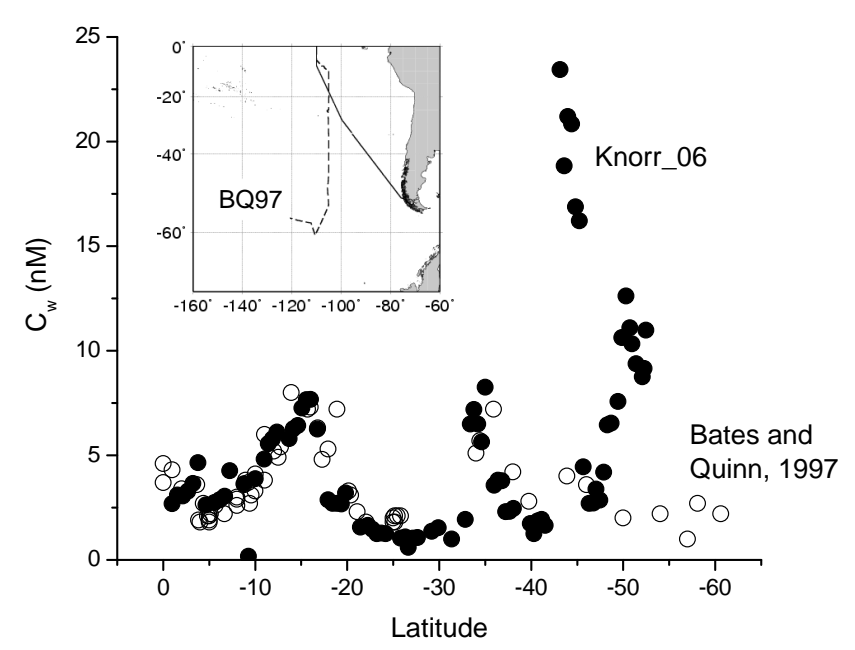

Fig. 5. Latitudinal comparison of surface seawater DMS concentrations from Knorr_06 (closed circles) and Bates and Quinn (1997) (BQ97, open circles). The map inset depicts the cruise track from Knorr_06 (black line) and that from BQ97 (grey line).

Liqui-Cel membrane is a bundle of many, much smaller diameter polypropylene tubes ( 300 micron OD) which gives it higher gas transfer efficiency. The concern with this type of equilibrator is the potential for biofouling, due to the high surface area of the bundle of tubing. Biofouling could likely lead to DMS production and an overestimate of ambient levels. On this cruise, there was one indication of spurious DMS production on DOY 22. The large increase in seawater concentration on DOY 22 was not accompanied by a similar increase in atmospheric levels. However, the rapid decline of the $20 \mathrm{nM}$ DMS pulse and the rapid decrease in DMS levels between the equatorial and gyre waters are not typical behaviors associated with biofouling.

Atmospheric DMS levels generally followed the same trends as the seawater DMS levels. The lowest levels were in the gyre region, between $0-0.3 \mathrm{ppb}$, and highest in the subpolar region, between $0.1-1.1 \mathrm{ppb}$. The atmospheric levels ranged between $0.45-0.7 \mathrm{pb}$ in the upwelling region. There were 3 instances when the surface seawater and atmospheric concentrations did not exhibit similar trends. The first was DOY 13 to 14 , during which time the atmospheric level increased by about a factor of 20 higher than the increase in seawater DMS (points labeled with grey dots in each graph). These points were measured in the region influenced by the coastal upwelling off of Peru. The back trajectories for these measurements indicated the origin of the air mass over the coast of Peru. The second instance was DOY 20, where the atmospheric DMS level increased again without an increase in surface seawater DMS. This was in the region of westerly flow with back trajectories indicating air mass origin over regions with enhanced chlorophyll concentration. This may indicate that the air levels were influenced by transport. As mentioned earlier, on DOY 22 there was an increase in sea-

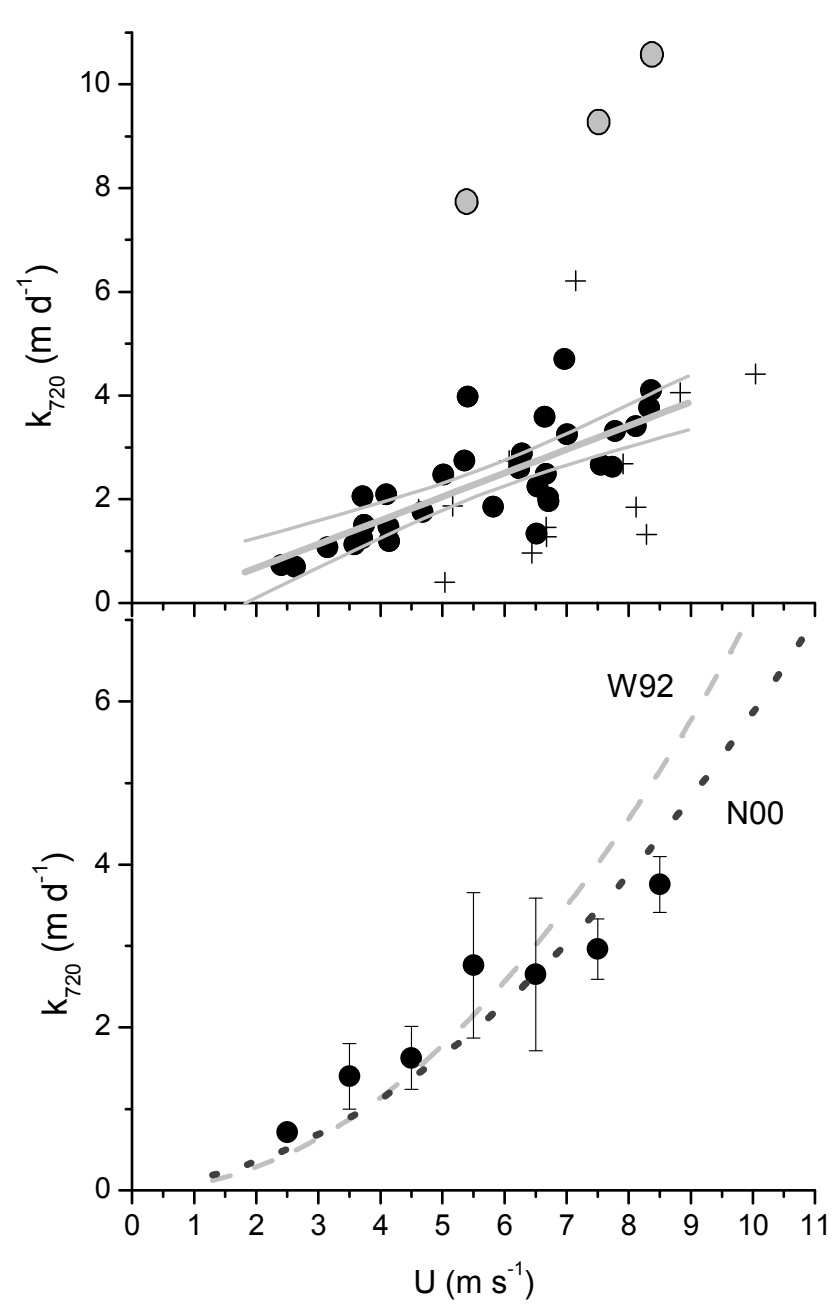

Fig. 6. Wind speed dependence of computed gas transfer coefficient normalized to $\mathrm{Sc}=720$. Top panel - best quality 1 -h $k$ values (closed circles) and lower quality $k$ values (plus signs). The solid grey lines are a linear fit to the data with $95 \%$ confidence bands. Bottom panel $-k$ values binned in $1 \mathrm{~ms}^{-1}$ intervals. Error bars are \pm 1 s.e. Gas transfer parameterizations of Wanninkhof (1992; W92 dashed grey line), and Nightingale et al. (2000a; N00, dotted black line), normalized to $\mathrm{Sc}=720$ are also shown. Grey closed circles indicate outlier points discussed in text.

water DMS levels without the equivalent increase in atmospheric DMS. In addition to the possibility of biofouling, this increase could be due to near surface seawater concentration gradients. This possibility also seems unlikely because the wind speeds were high enough during this period to cause increased mixing in the water column. It is also possible that the patch of increased DMS levels was highly localized and did not influence the air/sea flux over the footprint of the measurement. 


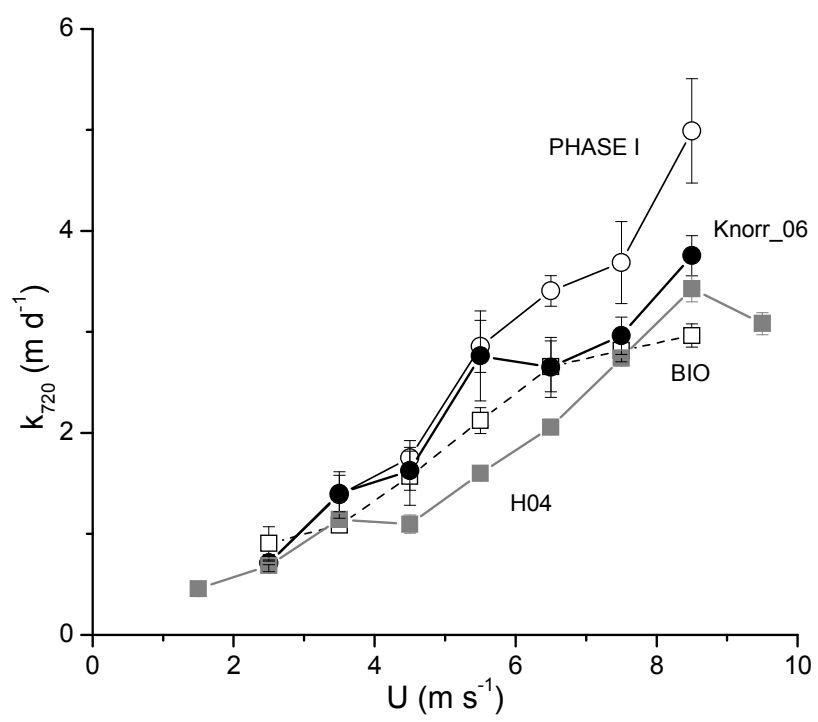

Fig. 7. Wind speed dependence of computed gas transfer coefficients from this work (solid black circles), the PHASE I (open circles) cruise, H04 (grey closed squares), and the BIO cruise (open squares), normalized to $\mathrm{Sc}=720$. All cruises binned by wind speed. Error bars represent the standard error of the mean (if error bars are not visible they are the size of the symbol).

3.2 Knorr_06 DMS air/sea fluxes and gas transfer coefficients

The measured air/sea DMS fluxes on this cruise were uniformly from sea to air, with a lognormal frequency distribution (Fig. 4). Average fluxes for the upwelling, gyre, and subpolar oceanographic regions were $17.6 \pm 17.2 \mu \mathrm{mol} \mathrm{m}^{-2} \mathrm{~d}^{-1}(\mathrm{n}=22), 5.74 \pm 6.57 \mu \mathrm{mol} \mathrm{m}^{-2} \mathrm{~d}^{-1}$ $(\mathrm{n}=22)$, and $5.54 \pm 2.53 \mu \mathrm{mol} \mathrm{m}^{-2} \mathrm{~d}^{-1}(\mathrm{n}=11)$, respectively. Gas transfer coefficients were computed by dividing the observed air/sea fluxes by the air/sea concentration differences. For comparison to other data, the computed transfer coefficient values were normalized to a Schmidt number (Sc) of 720 (DMS at $25^{\circ} \mathrm{C}$; Saltzman et al., 1993) based on the sea surface temperature of the individual measurements, and assuming a Sc${ }^{-1 / 2}$ dependence (Watson et al., 1991). These $k_{720}$ values ranged between $0.5-11 \mathrm{~m} \mathrm{~d}^{-1}$ (Fig. 6). There are three notable outliers in the data with respect to the wind speed dependence. These data correspond to the anomalously high fluxes measured in the equatorial upwelling region, on DOY 13 to 14 . The mean atmospheric DMS levels were anomalously high during these flux measurements, compared to the surrounding data. However, seawater DMS levels were only slightly elevated. There is no evidence for atypical analytical error associated with these measurements. The data are shown in Fig. 6 (top), but excluded from the discussion of the wind speed dependence of $k$ below. There are also lower quality $k$ values shown in the top panel of Fig. 6, which are not included in the discussion of the wind speed dependence of $k$. These data points either had apparent wind directions of \pm 60 to 90 from the mast or had $1 \sigma /$ mean $C_{w}$ values greater than $30 \%$, and correspond to the fluxes indicated with plus signs in Fig. 4.

The gas exchange coefficients from Knorr_06 exhibit a positive, roughly linear dependence on wind speed. A linear regression of $k$ vs. $U$, using only the highest quality data, gave the relationship $k=0.46^{*} U-0.24\left(r^{2}=0.59\right)$. The $k$ vs. $U$ relationship is similar to the Wanninkhof (1992) parameterization at the lower end of the wind speeds encountered in this cruise $\left(2\right.$ to $\left.6 \mathrm{~ms}^{-1}\right)$. However, at wind speeds higher than $6 \mathrm{~ms}^{-1}$, the data from this study show no evidence of a quadratic relationship to wind speed. The N00 wind speed relationship, which has a lower slope than the W92 quadratic relationship, is in better agreement with the Knorr_06 data at all wind speeds.

\subsection{Comparison with previous eddy covariance DMS mea-} surements

Three previous studies have reported DMS eddy covariance fluxes from the open ocean, using measurement techniques similar to this work. Huebert et al. (2004) measured DMS fluxes in the Eastern Pacific during November 2003 (H04), Blomquist et al. (2006) measured DMS fluxes in the Sargasso Sea in summer 2004 (BIO), and Marandino et al. (2007) measured DMS fluxes in the western/central equatorial and North Pacific during May-July 2004 (PHASE I). Figure 7 is a plot of $k$ vs. wind speed for all of the cruises. There is good agreement between all of the datasets at wind speeds lower than $4 \mathrm{~ms}^{-1}$ and considerable overlap between PHASE I, BIO, and this work up to $6 \mathrm{~ms}^{-1}$. The data from H04 are slightly lower than the other studies, particularly in the wind speed range of 4 to $6 \mathrm{~ms}^{-1}$. At wind speeds higher than $6 \mathrm{~ms}^{-1}$, the PHASE I gas transfer coefficients are significantly higher than all of the other datasets and exhibit steeper wind speed dependence. If it is assumed that all of the relationships presented are linear, the range of slopes of the $k_{\mathrm{DMS}}$ vs. $U$ relationship is about $\pm 28 \%$.

There is some indication of a sea surface temperature trend in the gas transfer coefficients for the different cruises. PHASE I in the western/central Pacific was warmest, with temperatures up to $30^{\circ} \mathrm{C}$, and that cruise exhibits the highest gas transfer coefficients. H04 in the wintertime eastern equatorial Pacific had the lowest sea surface temperatures, approximately $23^{\circ} \mathrm{C}$, and exhibited the lowest gas transfer coefficients. The two other cruises had intermediate temperatures and gas transfer coefficients. There is no obvious reason why this relationship should occur and further measurements under a wider range of conditions will be needed in order to validate the trend.

The differences in wind speed-dependence of $\mathrm{k}$ among these studies may reflect real differences in gas exchange in the different environments sampled, due to variations in microlayers, boundary layer dynamics, wind wave interactions, 
etc. However, methodological differences cannot be ruled out entirely. This study and Marandino et al. (2007) employed a correction to compensate for attenuation of high frequency DMS fluctuations in inlet tubing. This correction is based on the assumed similarity in frequency content of DMS flux and sensible heat flux, as measured on the bow mast. Because both the Knorr_06 and PHASE I cruise data were treated identically, this correction does not explain the differences between them. Huebert et al. (2004) and Blomquist et al. (2006) used shorter lengths of inlet tubing with less attenuation and did not perform the high frequency correction. Huebert et al. (2004) estimated 3-8\% loss at $6 \mathrm{~ms}^{-1}$, based on similarity to water vapor fluxes. Therefore, this is a small effect at the low wind speeds characterizing most of the DMS data. However, at higher wind speeds, the uncorrected data may underestimate the actual flux.

The use of $\mathrm{Sc}^{-1 / 2}$ to normalize the data from the various studies may also introduce uncertainty into the comparison of data sets collected at different sea surface temperatures. Deliberate tracer experiments by Watson et al. (1992) and Nightingale et al., (2000b) support a Sc$c^{-1 / 2}$ dependence of gas transfer for the wind speeds sampled here. However, relatively few such studies have been carried out. Asher et al. (2004) noted that $\mathrm{Sc}^{-1 / 2}$ did not correctly describe the relationship between $k_{\text {heat }}$ and $k_{\mathrm{CO}_{2}}$ observed in GASEX-01. They argued that $\mathrm{Sc}$-dependence may vary based on the conditions, as predicted by surface penetration theory (Harriott, 1962). Variations in Sc-dependence alone are unlikely to explain the variability between the various $k_{\mathrm{DMS}}$ studies. For example, a Sc${ }^{-1.4}$ dependence would be needed to reconcile the slopes of the PHASE I and Knorr_06 data sets.

3.4 Comparison with previous eddy covariance $\mathrm{CO}_{2}$ measurements

Figure 8 is a comparison of the GASEX 1998 and 2001 (McGillis et al., 2001, 2004) eddy covariance $\mathrm{CO}_{2}$ measurements with the DMS measurements from this study. The three cruises exhibit clear differences in the $k$ vs. $U$ relationship. As discussed earlier, the $k$ values from Knorr_06 have a linear relationship with wind speed. GASEX-98 appears to have a cubic dependence on wind speed, with relatively high $k$ values at 1 and $2 \mathrm{~ms}^{-1}$. GASEX-01 shows almost no dependence on wind speed, at least up to $7 \mathrm{~ms}^{-1}$. The GASEX$01 k$ values are the highest of all three cruises, GASEX-98 is lowest, and the data from this study are intermediate. Above $7 \mathrm{~ms}^{-1}$ there is limited data, but good agreement between all three cruises.

Again, there appears to be some relationship between sea surface temperature and $k$. Temperature affects gas transfer via bubble breaking, through its effect on solubility and Schmidt number. At the low to intermediate wind speed conditions of these studies, bubble transfer is not believed to be a significant component of DMS gas transfer (Woolf, 1997; Blomquist et al., 2006). However, bubbles may be impor-

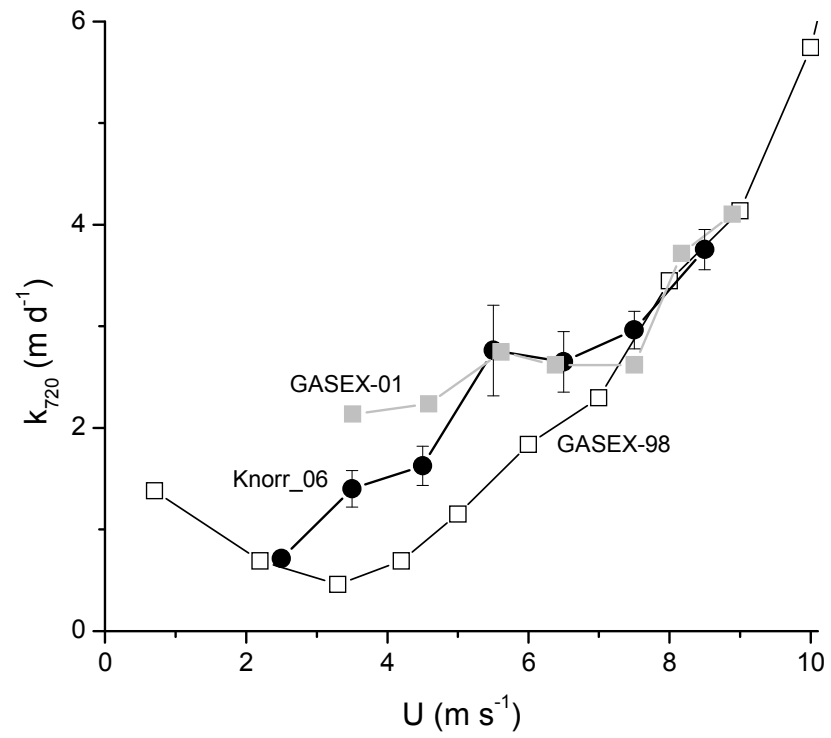

Fig. 8. Wind speed dependence of computed gas transfer coefficients from this work (solid black circles), the GASEX 1998 (McGillis et al., 2001) cruise (open squares), and the GASEX 2001 (McGillis et al., 2004) cruise (grey closed squares), normalized to $\mathrm{Sc}=720$. Error bars represent \pm 1 s.e.

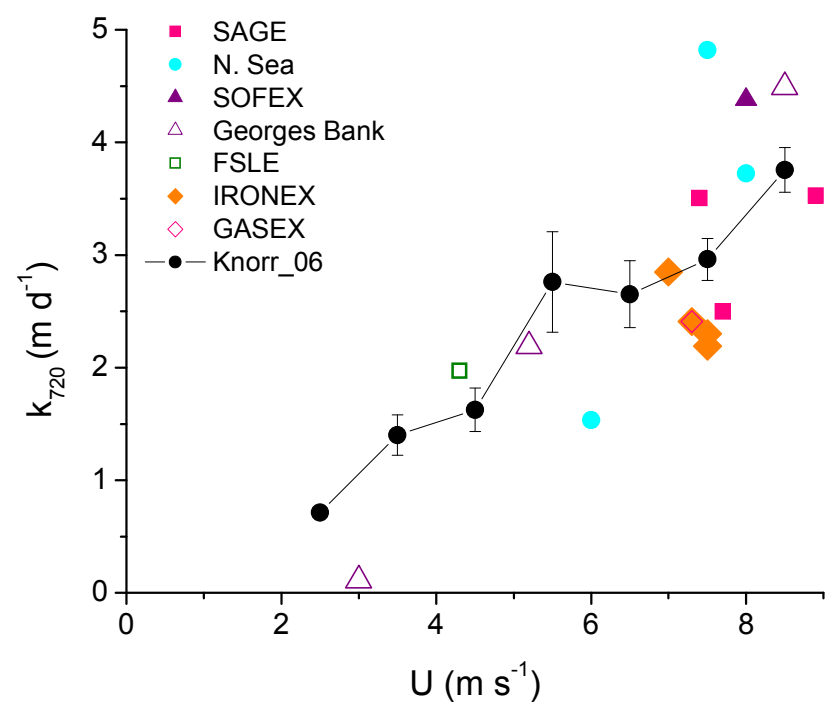

Fig. 9. Comparison between $k_{720}$ for DMS measured in this study and those measured by various dual tracer experiments. The Knorr_06 data has been binned by wind speed and error bars are the standard error of the mean. All the data has been normalized to a $\mathrm{Sc}=720$.

tant for $\mathrm{CO}_{2}$ at wind speeds as low as $5 \mathrm{~ms}^{-1}$ (Woolf, 1997). The effect of bubbles may therefore partially explain the difference between $k$ values for the GASEX cruises. However, the functionality of the wind speed dependence is opposite to that found in the DMS data comparison (i.e. the warmest $\mathrm{CO}_{2}$ data set has little wind speed dependence but 

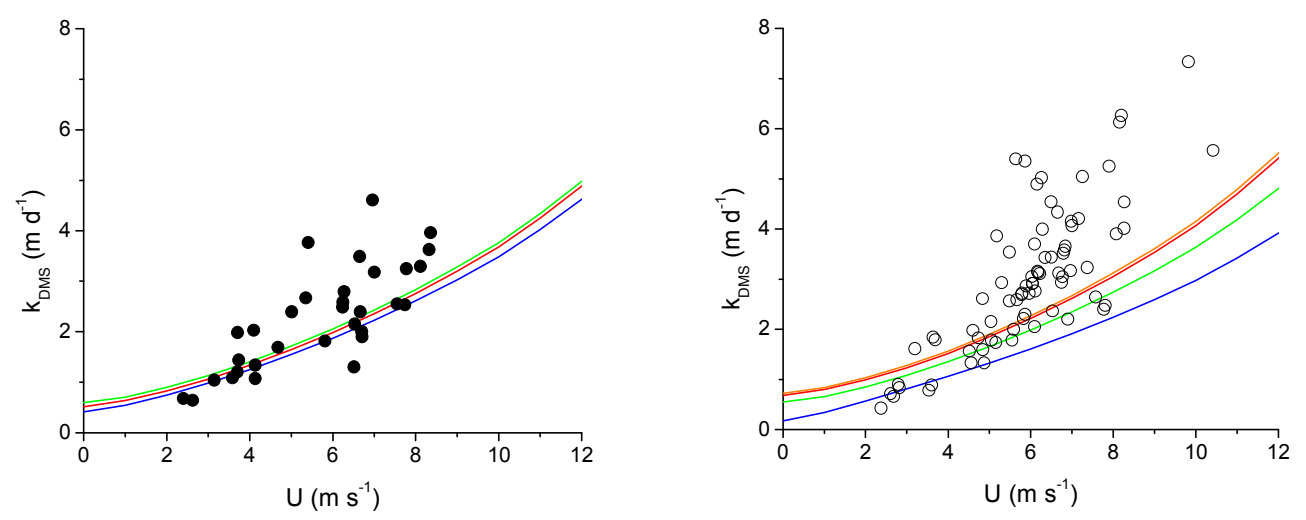

Fig. 10. Modeled and measured wind speed dependence of the gas transfer coefficient using the NOAA-COARE model. Left panel Knorr_06. The red, green, and blue lines represent modeled $k$ values for the upwelling, gyre, and subpolar regions, respectively. Right panel - PHASE I cruise. The red, orange, green, and blue lines represent modeled $k$ values for the warm pool, equatorial upwelling, gyre, and subpolar front regions, respectively. Solid black circles are measured $k$ values from Knorr_06 and open circles are PHASE I measured $k$ values. The $k$ values are not normalized by Schmidt number. Modeled $k$ values include bubble parameterization. Model tunable parameters were $\mathrm{A}=1.3$ and $\mathrm{B}=1.0$.

the warmest DMS data has the highest wind speed dependence). McGillis et al. (2004) hypothesized that in certain oceanic regions the diurnal heat budget may be the primary physical forcing on gas exchange. Diurnal variations in solar insolation drive stratification and buoyancy effects at the sea surface, both of which enhance gas exchange. Stratification due to daytime insolation leads to momentum trapping and greater turbulence, while nighttime sea surface cooling leads to greater buoyancy driven gas exchange. This hypothesis could explain the possible sea surface temperature trend in $k$ vs. $U$ and the lack of a significant wind speed dependence in the GASEX 2001 data. However, the western/central Pacific PHASE I cruise was in a region with similar solar insolation patterns and the wind speed dependence of $k$ was much greater than that of GASEX-01.

\subsection{Comparison with dual tracer studies}

Figure 9 is a comparison between this data and several dual tracer studies (SAGE-Ho et al., 2006; N. Sea-Nightingale et al., 2000b; SOFEX-Wanninkhof et al., 2004; Georges BankWanninkhof et al., 1993; FSLE-Wanninkhof et al., 1997; IRONEX-Nightingale et al., 2000a; GASEX-McGillis et al., 2001). The dual tracer $k$ values are in good agreement with the DMS $k$ values over the wind speed range measured during Knorr_06. It is apparent that the functional form of the dual tracer $k$ wind speed dependence is also basically linear, but the low point at $3 \mathrm{~ms}^{-1}$ has a big effect on the fit to the data. If that point is neglected, the $k$ vs. $U$ slope for the dual tracers is very similar to that of the DMS values. This is encouraging because the dual tracer studies were performed in widely different oceanographic regions from this study. There is general agreement between $k$ values measured using eddy covariance techniques and dual tracer techniques and $k$ values for $\mathrm{DMS}, \mathrm{CO}_{2}$, and $\mathrm{He} / \mathrm{SF}_{6}$. Since $\mathrm{He} / \mathrm{SF}_{6}$ are inert gases, this similarity may indicate that biological and chemical sources and losses in the sea surface do not affect the gas transfer coefficient of DMS. There is no indication of a sea surface temperature trend in the dual tracer gas transfer coefficients.

3.6 Comparison of DMS measurements with the NOAA/COARE gas transfermodel

The NOAA/COARE gas transfer model is a parameterization that estimates gas transfer coefficients based on measurable bulk parameters, such as wind speed, sea surface temperature, seawater specific humidity, air temperature and humidity, downwelling shortwave radiation, net longwave radiation, and air/sea concentration gradient (Fairall et al., 2000; Hare et al., 2004). Turbulent wind and buoyancydriven transfer in the air and turbulent transfer in the water are parameterized using Monin-Obhakov similarity theory, with the TOGA-COARE 3.0 bulk parameterizations of heat, moisture, and momentum (Fairall et al., 1996b, 2000). Transport through the interfacial sublayers is governed by diffusion, dissipation, and buoyancy. In this model, a Saunders coefficient is used to describe the contribution of the total wind stress acting tangentially at the surface to drive mixing of the viscous ocean side sublayer (Saunders, 1967; Fairall et al., 1996b). This coefficient encapsulates contributions to mixing from both shear and buoyancy. The model also incorporates gas transfer via bubbles, using a parameterization similar to that of Woolf (1997). Bubble transfer is not important for DMS at the wind speeds discussed here.

Gas transfer coefficients for DMS were computed using the NOAA/COARE model, for 7 scenarios representing mean conditions of the various oceanographic regions from 
Table 1. Inputs for each NOAA/COARE model run $^{a}$.

\begin{tabular}{llllll}
\hline Model run & $T_{s}\left({ }^{\circ} \mathrm{C}\right)$ & $T_{a}\left({ }^{\circ} \mathrm{C}\right)$ & $q_{s}(\mathrm{~g} / \mathrm{kg})$ & $q_{a}(\mathrm{~g} / \mathrm{kg})$ & Latitude \\
\hline PHASE I warm pool region & 29.57 & 28.62 & 25.82 & 18.43 & $8^{\circ} \mathrm{N}$ \\
PHASE I equatorial region & 28.87 & 28.19 & 24.79 & 18.14 & $3^{\circ} \mathrm{N}$ \\
PHASE I gyre region & 23.25 & 22.03 & 17.79 & 11.62 & $15^{\circ} \mathrm{N}$ \\
PHASE I subpolar front region & 15.03 & 13.79 & 10.54 & 8.02 & $45^{\circ} \mathrm{N}$ \\
Knorr_06 upwelling region & 24.41 & 23.92 & 18.98 & 14.36 & $8^{\circ} \mathrm{S}$ \\
Knorr_06 gyre region & 24.89 & 23.82 & 19.54 & 12.95 & $22^{\circ} \mathrm{S}$ \\
Knorr_06 subpolar region & 21.99 & 21.44 & 16.38 & 12.71 & $34^{\circ} \mathrm{S}$ \\
\hline
\end{tabular}

$a$ All runs were carried out using downwelling solar flux = $141 \mathrm{~W} \mathrm{~m}^{-2}$, downward IR flux $=419 \mathrm{~W} \mathrm{~m}^{-2}$, rain rate $=0 \mathrm{~mm} \mathrm{~h}^{-1}$, planetary boundary layer depth $=600 \mathrm{~m}$, atmospheric pressure $=$ 1010 mbar, sensor measurement height $=10 \mathrm{~m}$, cool skin switch on $=1$, wave switch off $=0$. Wind speed range for each run was 0 to $15 \mathrm{~ms}^{-1}$.

Knorr_06 and the western/central Pacific PHASE I cruise (Table 1). The NOAA/COARE model exhibits reasonable agreement with the low wind-speed gas transfer coefficients ( 2 to $4 \mathrm{~ms}^{-1}$ ) from this cruise and the PHASE I cruise. However, the model underestimates the gas transfer coefficients and the slope of the observed $k_{\mathrm{DMS}}$ vs. $U$ relationship (Fig. 10) at intermediate wind speeds (4 to $8 \mathrm{~ms}^{-1}$ ). This result is not sensitive to minor changes in the input conditions (e.g. air temperature, sea surface temperature), as shown by the curves in Fig. 10. The slope of $k$ vs. $U$ in the NOAA/COARE model is strongly influenced by the parameterization of transport through the diffusive sublayer. In the NOAA/COARE model, flux $(F)$ is parameterized as follows:

$F=\frac{u_{* a} \Delta C}{\left(r_{a}+r_{w}\right)}$

in which $u_{* a}$ is the friction velocity in air side units, $\Delta C$ is the air/sea concentration gradient, $r_{a}$ is the air side resistance to transfer and $r_{w}$ is the water side resistance to transfer. A two layer model is used to parameterize $r_{w}$,

$r_{w}=\sqrt{\rho_{w} / \rho_{a}}\left[h_{w} S_{c w}^{1 / 2}+\ln \left(z_{w} / \delta_{w}\right) / \kappa\right]$

where the term on the left of the plus sign is the diffusive sublayer and the term on the right is the turbulent sublayer, $\rho$ is the density of air and water (subscript $a$ and $w$, respectively), $z_{w}$ is the reference depth of the water, $\delta$ is depth of the diffusive sublayer, and $\kappa$ is the von Karman constant (0.4). Generally, the diffusive term is an order of magnitude larger than the turbulent term, indicating that there is more resistance to flux in the diffusive sublayer than in the turbulent sublayer. The wind speed dependence of the diffusive sublayer is influenced by the $h_{w}$ term,

$h_{w}=\frac{\Lambda}{A \phi}$

where $\Lambda=13.3$ (Soloviev and Schlussel, 1994), $A$ is a tunable constant, and $\phi$ is an empirical parameterization that incorporates the Saunders coefficient (Fairall et al., 1996b) and

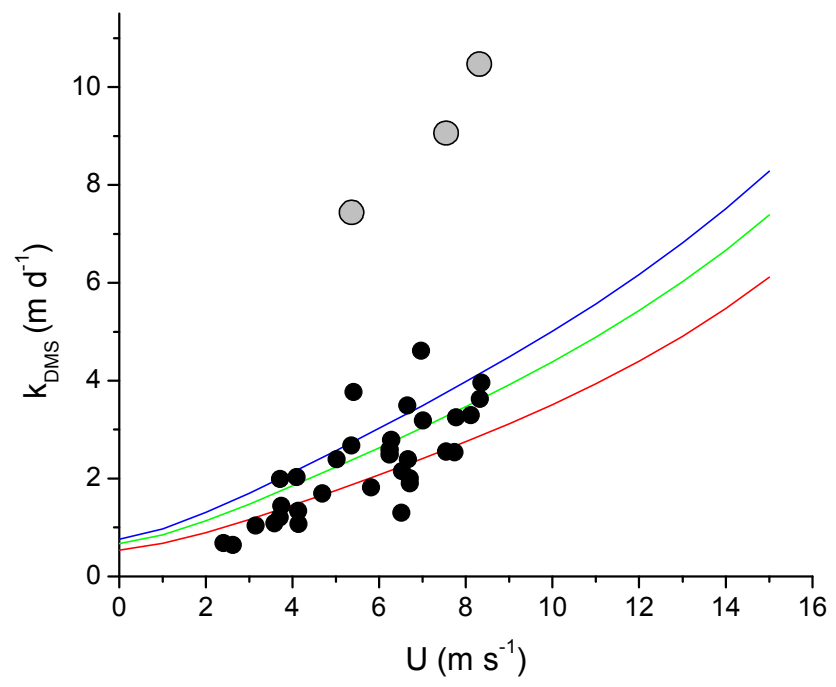

Fig. 11. The wind speed dependence of the DMS gas transfer coefficient measured in Knorr_06 (closed circles) compared to various NOAA/COARE model runs with different tunable parameter $A$ values ( $A=2.0$, blue line; $A=1.7$, green line; $A=1.3$, red line).

water side buoyancy effects. For the values of buoyancy flux relevant to these studies, $\phi$ approaches an asymptotic value of 1 at wind speeds greater than about $3 \mathrm{~ms}^{-1}$. At lower wind speeds, $\phi$ has the effect of enhancing gas transfer and "flattening" the $k$ vs. $U$ relationship.

The NOAA/COARE model was successfully used to simulate the $k_{\mathrm{CO}_{2}}$ vs. $U$ relationship obtained during GASEX98, with adjustment of $A$ and the bubble-exchange scaling parameter $B$ (Woolf, 1997). Hare et al. (2004) showed that NOAA/COARE does not simulate the much weaker wind speed dependence of $k_{\mathrm{CO}_{2}}$ observed on GASEX-01, and attributed this to the oversimplification of mixed layer dynamics in the model. Blomquist et al. (2006) adjusted of the tunable parameters of the NOAA/COARE model to simulate the $k_{\mathrm{DMS}}$ data from $\mathrm{BIO}$ and $\mathrm{H} 04$. They found reasonable agreement between the modeled and measured values, but the slope of the wind speed dependence was slightly too low.

Figure 11 illustrates the sensitivity of the model to variations in the $A$ parameter. The Knorr_06 data was reasonably well simulated with $A=1.7$. The model overestimates $k_{\text {DMS }}$ at the lowest wind speeds because increasing the $A$ value increases the $k$ values over the entire wind speed range. It is not possible to achieve similar agreement with the PHASE I data simply by increasing the value of $A$. Increasing $A$ to the level needed to match the slope of that data elevates $k$ at low wind speeds to unrealistic levels. Matching both the low wind speed $k_{\mathrm{DMS}}$ and the slope of $k_{\mathrm{DMS}}$ vs. $U$ for PHASE I would require altering the physical parameterization of gas exchange in the model. 


\subsection{Possible influence of near surface gradients on $k_{\mathrm{DMS}}$}

The DMS-based gas transfer coefficients presented in this and other similar studies could be affected by near surface concentration gradients. The gas transfer coefficients computed in this study are based on seawater DMS measurements from the ship bow pumping system, with an average depth of $5 \mathrm{~m}$. It is generally assumed that DMS measurements from bow pumping systems represent the sea surface bulk concentration (Kettle et al., 1999 and references therein). The calculation of $k$ from the observed flux implicitly assumes that the near surface (e.g. 0 to $5 \mathrm{~m}$ ) represents a layer of constant flux, in which DMS is neither produced nor destroyed. However, very few studies have examined the validity of this assumption. Near surface gradients can arise from photochemical loss and biological production/loss (Kieber and Jiao, 1996). Stratification caused by strong salinity gradients or solar heating can isolate the surface from waters below, leading to depletion of DMS.

Most published depth profiles collected with CTDs have only one or two samples in the upper $5 \mathrm{~m}$ (e.g. Dacey et al., 1998; Wong et al., 2005). Such studies exhibit wide variability in profile shapes, including uniform profiles, profiles indicating both surface depletion and enhancement, and profiles with alternating sharp positive and negative gradients. Zemmelink et al. (2005) examined the difference in DMS levels between $10 \mathrm{~cm}$ and $5 \mathrm{~m}$ on several different days in coastal waters off Martha's Vineyard. They observed depletions of DMS near the surface ranging from 10 to $66 \%$. They also measured DMSP, DMSO, and bacterial number and deduced that the DMS gradient was a result of ventilation since DMSP and bacteria gradients were nearly uniform. Simultaneous flux measurements would allow this inference to be tested, but such studies have not yet been carried out.

The interpretation of the DMS-based gas transfer coefficients would also be affected by biological or chemical enrichment/depletion of DMS in the sea surface microlayer. There is a very limited basis on which to assess such processes because of the difficulty of measuring microlayer gas concentrations. Both enrichment and depletion have been observed in various studies, but the applicability of these measurements to the open ocean are unclear (Matrai et al., 2008; Yang et al., 1999, 2005a, 2005b, 2008; Zemmelink et al., 2005a, b).

\section{Conclusion}

The gas transfer coefficients derived from the Knorr_06 transect in the eastern South Pacific are in reasonable agreement with three prior open ocean eddy covariance studies of DMS gas transfer, covering a variety of oceanographic conditions. $k_{\text {DMS }}$ is linear in wind speed over the range covered in these studies ( 2 to $8 \mathrm{~ms}^{-1}$ ). The slopes of $k_{\mathrm{DMS}}$ vs. $U$ relationships from the four studies vary by about $\pm 28 \%$, with the Knorr_06 at the low end of the range.

The $k$ vs. $U$ relationship from Knorr_06 has a slope intermediate between the two very different $\mathrm{CO}_{2}$ eddy covariance data sets from GASEX-98 and GASEX-01 in the North Atlantic and Eastern tropical Pacific, respectively. None of the DMS studies exhibit the striking lack of wind speeddependence from 3 to $7 \mathrm{~ms}^{-1}$ observed on GASEX-01. That is surprising, given that both Knorr_06 and PHASE I sampled waters in the eastern, central, and western tropical Pacific subject to similar strong diurnal forcing of water column stability and vertical mixing encountered on GASEX-01. The apparent difference in behavior of $k_{\mathrm{CO}_{2}}$ and $k_{\mathrm{DMS}}$ in tropical waters remains unexplained, and will probably require more detailed field measurements to resolve.

The NOAA/COARE gas transfer model under-predicts the wind speed dependence of $k_{\mathrm{DMS}}$ data from this and previous DMS field studies. This is particularly striking for the PHASE I data. As noted by Hare et al. (2004), the model does not capture the full dynamics of the surface mixed layer, particularly with respect to daytime stratification and nocturnal convective mixing. However, based on the results of GASEX-01, such processes tend to flatten, rather than steepen the $k$ vs. $U$ slope (McGillis et al., 2004). It is possible that the relatively steep slopes of the $k_{\mathrm{DMS}}$ vs. $U$ are an "artifact" of systematic near surface gradients in DMS. However, if present, such gradients would likely cause diurnal variability in $k_{\text {DMS }}$ which is not evident in the Knorr_06 or PHASE I data sets.

There are many challenges involved in unraveling the complex physics, chemistry, and perhaps biology of air/sea gas exchange. Current understanding is observationally limited, and progress will come from the application of a diverse set of techniques for probing the air/sea interface. Because of the many scales of motion involved in turbulent, near surface processes no single tracer can capture the full behavior of the interface. The DMS eddy covariance measurements to date represent a coherent dataset with interesting similarities and differences from other measures of air/sea gas exchange. Further measurements of this type are needed in order to assess the full range of oceanic conditions and the relationship between this and other tracers.

Acknowledgements. We wish to thank WHOI, the captain and crew of the R/V Knorr, Cyril McCormick for outstanding technical support, and Chris Fairall for assistance with the NOAA/COARE model. This research was funded by NSF and is a contribution to the US SOLAS program.

Edited by: W. E. Asher 


\section{References}

Asher, W. E., Jessup, A. T., and Atmane, M. A.: Oceanic application of the active controlled flux technique for measuring air-sea transfer velocities of heat and gases, J. Geophys. Res.-Oceans, 109, C08S12, doi:10.1029/2003JC001862, 2004.

Bates, T. S. and Quinn, P. K.: Dimethylsulfide (DMS) in the equatorial Pacific Ocean (1982 to 1996): Evidence of a climate feedback?, Geophys. Res. Lett., 24, 861-864, 1997.

Blomquist, B. W., Fairall, C. W., Huebert, B. J., Kieber, D. J., and Westby, G. R.: DMS sea-air transfer velocity: Direct measurements by eddy covariance and parameterization based on the NOAA/COARE gas transfer model, Geophys. Res. Lett., 33, L07601, doi:10.1029/206GL025735, 2006.

Donelan, M. A. and Wanninkhof, R.: Gas transfer at water surfaces-concepts and issues, in: Gas Transfer at Water Surfaces, Donelan, M. A., Drennan, W. M., Saltzman, E. S., Wanninkhof, R., American Geophysical Union, Washington, DC, USA, 1-10, 2002.

Fairall, C. W., Bradley, E. F., Godfrey, J. S., Wick, G. A., Edson, J. B., and Young, G. S.: Cool-skin and warm-layer effects on sea surface temperature, J. Geophys. Res.-Oceans, 101, 1295-1308, 1996a.

Fairall, C. W., Bradley, E. F., Rogers, D. P., Edson, J. B., and Young, G. S.: Bulk parameterization of air-sea fluxes for Tropical Ocean Global Atmosphere Coupled Ocean Atmosphere Response Experiment, J. Geophys. Res.-Oceans, 101, 3747-3764, 1996b.

Fairall, C. W., Hare, J. E., Edson, J. B., and McGillis, W.: Parameterization and micrometeorological measurement of air-sea gas transfer, Bound.-Lay. Meteorol., 96, 63-105, 2000.

Hare, J. E., Fairall, C. W., McGillis, W. R., Edson, J. B., Ward, B., and Wanninkhof, R.: Evaluation of the National Oceanic and Atmospheric Administration/Coupled-Ocean Atmospheric Response Experiment (NOAA/COARE) air-sea gas transfer parameterization using GasEx data, J. Geophys. Res.-Oceans, 109, C08S11, doi:10.1029/2003JC001831, 2004.

Harriott, P.: A random eddy modification of the penetration theory, Chem. Eng. Sci., 17, 149-154, 1962.

Hintsa, E. J., Dacey, J. W. H., McGillis, W. R., Edson, J. B., Zappa, C. J., and Zemmelink, H. J.: Sea-to-air fluxes from measurements of the atmospheric gradient of dimethylsulfide and comparison with simultaneous relaxed eddy accumulation measurements, J. Geophys. Res.-Oceans, 109, C01026, doi:10.1029:2002JC001617, 2004.

Ho, D. T., Law, C. S., Smith, M. J., Schlosser, P., Harvey, M., and Hill, P.: Measurements of air-sea gas exchange at high wind speeds in the Southern Ocean: Implications for global parameterizations, Geophys. Res. Lett., 33, L16611, doi:10.1029/2006GL026817, 2006.

Huebert, B. J., Blomquist, B. W., Hare, J. E., Fairall, C. W., Johnson, J. E., and Bates, T. S.: Measurement of the sea-air DMS flux and transfer velocity using eddy correlation, Geophys. Res. Lett., 31, L23113, doi:10.1029/2004GL021567, 2004.

Kaimal, J. C., Izumi, Y., Wyngaard, J. C., and Cote, R.: Spectral Characteristics of Surface-Layer Turbulence, Q. J. Roy. Meteor. Soc., 98, 563-589, 1972.

Kettle, A. J., Andreae, M. O., Amouroux, D., Andreae, T. W., Bates, T. S., Berresheim, H., Bingemer, H., Boniforti, R., Curran, M. A. J., DiTullio, G. R., Helas, G., Jones, G. B., Keller, M. D., Kiene, R. P., Leck, C., Levasseur, M., Malin, G., Maspero, M., Matrai,
P., McTaggart, A. R., Mihalopoulos, N., Nguyen, B. C., Novo, A., Putaud, J. P., Rapsomanikis, S., Roberts, G., Schebeske, G., Sharma, S., Simo, R., Staubes, R., Turner, S., and Uher, G.: A global database of sea surface dimethylsulfide (DMS) measurements and a procedure to predict sea surface DMS as a function of latitude, longitude, and month, Global Biogeochem. Cy., 13, 399-444, 1999.

Kieber, D. J., Jiao, J. F., Kiene, R. P.; and Bates, T. S.: Impact of dimethylsulfide photochemistry on methyl sulfur cycling in the equatorial Pacific Ocean, J. Geophys. Res.-Oceans, 101, 37153722, 1996.

Marandino, C. A., De Bruyn, W. J., Miller, S. D., and Saltzman, E. S.: Eddy correlation measurements of the air/sea flux of dimethylsulfide over the North Pacific Ocean, J. Geophys. Res.Atmos., 112, D03301, doi:10.1029/2006JD007293, 2007.

Matrai, P. A., Tranvik, L., Leck, C., and Knulst, J. C.: Are high Arctic surface microlayers a potential source of aerosol organic precursors?, Mar. Chem., 108, 109-122, 2008.

McGillis, W. R., Edson, J. B., Hare, J. E. and Fairall, C. W.: Direct covariance air-sea $\mathrm{CO}_{2}$ fluxes, J. Geophys. Res.-Oceans, 106, 16729-16745, 2001.

McGillis, W. R., Edson, J. B., Zappa, C. J., Ware, J. D., McKenna, S. P., Terray, E. A., Hare, J. E., Fairall, C. W., Drennan, W., Donelan, M., DeGrandpre, M. D., Wanninkhof, R., and Feely, R. A.: Air-sea $\mathrm{CO}_{2}$ exchange in the equatorial Pacific, J. Geophys. Res.-Oceans, 109, C08S02, doi:10.1029/2003JC002256, 2004.

Nightingale, P. D., Liss, P. S., and Schlosser, P.: Measurements of air-sea gas transfer during an open ocean algal bloom., Geophys. Res. Lett., 27, 2117-2120, 2000a.

Nightingale, P. D., Malin, G., Law, C. S., Watson, A. J., Liss, P. S., Liddicoat, M. I., Boutin, J., and Upstill-Goddard, R. C.: In situ evaluation of air-sea gas exchange parameterizations using novel conservative and volatile tracers, Global Biogeochem. Cy., 14, 373-387, 2000b.

Saltzman, E. S., King, D. B., Holmen, K., and Leck, C.: Experimental-Determination of the Diffusion-Coefficient of Dimethylsulfide in Water, J. Geophys. Res.-Oceans, 98, 1648116486, 1993.

Saunders, P. M.: Temperature at Ocean-Air Interface, J. Atmos. Sci., 24, 269-273, 1967.

Soloviev, A. V. and Schlussel, P.: Parameterization of the Cool Skin of the Ocean and of the Air-Ocean Gas Transfer on the Basis of Modeling Surface Renewal, J. Phys. Oceanogr., 24, 1339-1346, 1994.

Soloviev, A. V. and Schlussel, P.: Evolution of cool skin and direct air-sea gas transfer coefficient during daytime, Bound.-Lay. Meteorol., 77, 45-68, 1996.

Soloviev, A. V.: Coupled renewal model of ocean viscous sublayer, thermal skin effect and interfacial gas transfer velocity, J. Marine. Syst., 66, 19-27, 2007.

Wanninkhof, R.: Relationship between Wind-Speed and GasExchange over the Ocean, J. Geophys. Res.-Oceans, 97, 73737382, 1992.

Wanninkhof, R., Asher, W., Weppernig, R., Chen, H., Schlosser, P., Langdon, C., and Sambrotto, R.: Gas Transfer Experiment on Georges Bank Using 2 Volatile Deliberate Tracers, J. Geophys. Res.-Oceans, 98, 20 237-20 248, 1993.

Wanninkhof, R., Hitchcock, G., Wiseman, W. J., Vargo, G., Ortner, P. B., Asher, W., Ho, D. T., Schlosser, P., Dickson, M. L., 
Masserini, R., Fanning, K., and Zhang, J. Z.: Gas exchange, dispersion, and biological productivity on the west Florida shelf: Results from a Lagrangian tracer study, Geophys. Res. Lett., 24, 1767-1770, 1997.

Wanninkhof, R., Sullivan, K. F., and Top, Z.: Air-sea gas transfer in the Southern Ocean, J. Geophys. Res.-Oceans, 109, C08S19, doi:10.1029/2003JC001767, 2004.

Watson, A. J., Upstill-Goddard, R. C., and Liss, P. S.: Air Sea GasExchange in Rough and Stormy Seas Measured by a Dual-Tracer Technique, Nature, 349, 145-147, 1991.

Woolf, D. K.: Bubbles and their role in gas exchange, in: The Sea Surface and Global Change, R. A. D. a. P. S. Liss, Cambridge University Press, New York, USA, 173-205, 1997.

Yang, G. P.: Dimethylsulfide enrichment in the surface microlayer of the South China Sea, Mar. Chem., 66, 215-224, 1999.

Yang, G. P., Levasseur, M., Michaud, S., and Scarratt, M.: Biogeochemistry of dimethylsulfide (DMS) and dimethylsulfoniopropionate (DMSP) in the surface microlayer and subsurface water of the western North Atlantic during spring, Mar. Chem., 96, 315329, 2005a.

Yang, G. P. and Tsunogai, S.: Biogeochemistry of dimethylsulfide (DMS) and dimethylsulfoniopropionate (DMSP) in the surface microlayer of the western North Pacific, Deep-Sea Res. Pt. I, 52, 553-567, 2005b.
Yang, G. P., Jing, W. W., Kang, Z. Q., Zhang, H. H., and Song, G. S.: Spatial variations of dimethylsulfide and dimethylsulfoniopropionate in the surface microlayer and in the subsurface waters of the South China Sea during springtime, Mar. Environ. Res., 65, 85-97, 2008.

Zemmelink, H. J., Gieskes, W. W. C., Klaassen, W., Beukema, W. J., de Groot, H. W., de Baar, H. J. W., Hintsa, E. J., McGillis, W. R., and Dacey, J. W. H.: Relaxed eddy accumulation measurements of the sea-to-air transfer of dimethylsulfide over the northeastern Pacific, J. Geophys. Res.-Oceans, 109, C01025, doi:10.1029/2002JC001616, 2004.

Zemmelink, H. J., Houghton, L., Dacey, J. W. H., Worby, A. P., and Liss, P. S.: Emission of dimethylsulfide from Weddell Sea leads, Geophys. Res. Lett., 32, L23610, doi:10.1029/2005GL024242, 2005a.

Zemmelink, H. J., Houghton, L., Sievert, S. M., Frew, N. M., and Dacey, J. W. H.: Gradients in dimethylsufide, dimethylsulfoniopropionate, dimethylsulfoxide, and bacteria near the sea surface, Mar. Ecol.-Prog. Ser., 295, 33-42, 2005 b. 